\title{
As dimensões político-sociais de uma epidemia: a paulicéia desvairada pela gripe espanhola
}

\author{
The sociopolitical dimensions of an epidemic: \\ São Paulo in the mad grip of the Spanish flu
}

\author{
Christiane Maria Cruz de Souza \\ Professora do Centro Federal de \\ Educação Tecnológica da Bahia (Cefet-BA) \\ Estrada Leopoldo Froés, 395/303 \\ 24360-005 Niterói - RJ - Brasil \\ christianecruz@hotmail.com
}

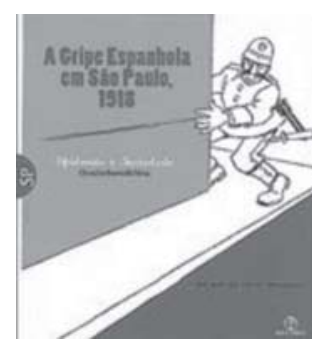

Cláudio Bertolli Filho. A gripe espanhola em São Paulo, 1918: epidemia e sociedade. Rio de Janeiro: Paz e Terra, 2003. 393 p.

\begin{abstract}
A partir das últimas décadas do século XX, a saúde e a doença têm se tornado temas prolíficos entre os cientistas sociais. O diálogo entre as ciências humanas e sociais e as ciências biomédicas ampliou o foco sobre o assunto, permitindo que o processo saúde-enfermidade fosse estudado não só como um problema em si, mas também como ferramenta para discutir as intricadas relações sociais e de poder, as concepções culturais, os valores sociais e as práticas institucionais de uma determinada sociedade.
\end{abstract}

Alguns estudos realizados dentro dessa temática partem do princípio de que as implicações das causas morbígenas sobre a vida ultrapassam o biológico, bem como julgam que a doença não pode ser examinada fora da estrutura social na qual está inserida. ${ }^{1}$ Considerando-se esse pressuposto, indivíduos e grupos sociais em tempos históricos e espaços geográficos diferentes produziram seus próprios modos de definir a etiologia, a transmissão, a terapia apropriada e os significados de uma doença. Essas definições refletem não só a mudança do conhecimento e das tecnologias médicas, mas também influências mais amplas, tais como convicções religiosas, obrigações de gênero, de nacionalidade, de etnias e de classe, além de políticas e responsabilidades estatais.

Nesse sentido, apesar de a doença ser um evento biológico imediato, com um repertório de práticas e construções verbais específicas que refletem a história institucional e intelectual da medicina, constituise, também, em um evento social, tornando-se uma ocasião potencial de desenvolvimento e de legitimação de políticas públicas, um aspecto do papel social e da identidade individual, uma sanção para valores culturais e um elemento de estruturação do saber médico em sua interação com o enfermo (Rosenberg, 1997, p. xiii).

Dentro de uma perspectiva histórica que propõe a interação poderosa entre cultura, história, medicina e sociedade, insere-se o estudo das epidemias. As crises epidêmicas provocadas por doenças contagiosas como a varíola, a febre amarela, a peste bubônica, a gripe e o cólera, passaram a ser objeto da história da medicina e da história sociocultural da doença, considerando-se as suas dimensões sociais, culturais e políticas. As relações entre o Estado, o conhecimento médico, as políticas de saúde pública, as exigências do sistema econômico, as percepções e 
representações das doenças e as respostas das pessoas comuns são pontos de discussão recorrentes nas abordagens historiográficas que tomam as epidemias como objeto de análise e reflexão. Entre os estudos das manifestações epidêmicas, desde a década de 1990, a gripe espanhola vem ocupando, de maneira crescente, as agendas de pesquisadores do Brasil e do mundo. ${ }^{2}$

A epidemia de influenza irrompeu em 1918, em meio à movimentação das tropas envolvidas na Primeira Guerra Mundial. Entre agosto e dezembro daquele ano, percorreu todos os continentes, atacando, com intensidade, as comunidades de surpresa e vitimando milhares de pessoas.

O exame superficial das diversas narrativas construídas sobre aquele evento pode detectar alguma similitude na maneira como os fatos se desenrolam, em diferentes realidades. Há uma espécie de dramaturgia comum às epidemias que, de modo geral, apresentam dilemas semelhantes, nascidos da necessidade de explicá-las e combatê-las, e as respostas parecem se repetir ao longo da história. Não obstante, é preciso considerar a complexidade das negociações acerca da definição e da resposta à doença, que envolve atores e ações diversos, em contextos, por vezes, multidimensionais.

O livro de Cláudio Bertolli Filho - A gripe espanhola em São Paulo, 1918: epidemia e sociedade - publicado pela Editora Paz e Terra em 2003, apresenta a versão paulistana da pandemia que varreu o mundo no segundo semestre de $1918 .{ }^{3} \mathrm{O}$ autor constrói sua narrativa na perspectiva da história social da saúde, tomando de empréstimo os conceitos da epidemiologia social que permitem enforcar o processo saúdeenfermidade a partir da realidade socioeconômica, sanitária e cultural das diversas camadas da sociedade paulistana.

Para compor o retrato da capital paulista sob a influência daquele dramático acontecimento, Bertolli Filho amplia o leque de informações, apoiando-se em fontes variadas: documentação administrativa, publicações médicas, dados estatísticos, relatórios hospitalares e de organizações religiosas, fontes iconográficas, narrativas de memorialistas, depoimentos orais, jornais diários, além da bibliografia específica. A imprecisão dos dados e o desencontro de informações da documentação produzida pelas instâncias administrativas justificam a amplitude das fontes utilizadas pelo pesquisador, preocupado em fugir da análise oficial da epidemia, que tendeu a minimizar os efeitos do flagelo para não contrariar a propalada imagem de progresso material e sanitário da 'Metrópole do Café'.

O mergulho do leitor na narrativa da gripe paulistana é facilitado pelo autor, que divide o livro em dez capítulos e desenha a história da cidade sob o ângulo da devastação provocada pela epidemia.

Logo de início, o autor ressalta "a necessidade de se observar a sociedade como um objeto de estudo marcado pela heterogeneidade", contrapondo a face moderna e civilizada da Paulicéia à "cidade suja e infecta do operariado e dos marginais, dos imigrantes e dos negros" (p. 33-7). Assim, no primeiro capítulo começa a ser esboçado o argumento central do livro, na medida em que o autor busca determinar a distribuição social das enfermidades na capital do estado de São Paulo. 
Para reforçar a sua argumentação, o autor traça o perfil patológico da cidade, relacionando-o com a realidade particular de cada grupo distrital. Segundo Bertolli Filho, a distribuição dos óbitos por doenças infecto-contagiosas estava diretamente relacionada à condição socioeconômica de cada grupo social e à infra-estrutura própria de cada área ocupada pelos diferentes estratos sociais do município.

Nessa perspectiva, apesar da estrutura de poder econômico da cidade e da associação das ciências biomédicas com a pretensa organização racional da sociedade paulistana, não havia uma distribuição eqüitativa e eficiente dos serviços e dos recursos de saúde pública. De acordo com Bertolli Filho, na capital paulista, as modalidades de habitações e os beneficiamentos públicos e privados estavam estreitamente vinculados ao nível socioeconômico do grupo ou grupos sociais predominantes em setores diversificados do espaço urbano, o que certamente influía nas condições gerais de saúde e de assistência prestada a cada coletividade.

Como os registros da mortalidade realizados pelo serviço sanitário paulista só lhe ofereciam uma visão parcial dos fatos, tendo em vista que nem todo doente chegava a óbito, Bertolli Filho passou a analisar a trajetória das epidemias no espaço urbano. Dessa maneira, o autor observou que algumas epidemias ou focos epidêmicos se restringiam a uma determinada região (um ou dois distritos ou mesmo uma rua). Além disso, o estudo da especificidade da doença permitiu que o pesquisador estabelecesse a relação entre agente etiológico, hospedeiro e ambiente, determinando a sua distribuição diferenciada no município de São Paulo. ${ }^{4}$

Tendo preparado tal alicerce, finalmente o autor começa a tecer a sua narrativa sobre a epidemia de gripe espanhola que incidiu sobre a cidade de São Paulo, num período estimado de 66 dias, entre 15 de outubro a 19 de dezembro de 1918. Para introduzir o assunto e ampliar o conhecimento do leitor sobre a influenza, o autor faz a caracterização da doença e apresenta a trajetória das epidemias e pandemias gripais desde a Antiguidade, refletindo sobre o conhecimento médicocientífico de cada época. A seguir, detém-se na pandemia de 1918, mapeando o itinerário da gripe no mundo até sua chegada ao Brasil, discutindo a sua origem e a sua denominação.

No capítulo seguinte, discute-se a precisão dos dados sobre a morbidade e a mortalidade por gripe registrados pelo Serviço Sanitário. Bertolli Filho considera que os dados computados, principalmente os relativos à morbidade, não corresponderiam à realidade. Essa imprecisão se deveu a uma somatória de fatores: a gripe não era uma doença de notificação obrigatória, nem todos os doentes tinham acesso aos serviços de saúde, faltavam funcionários na Repartição de Estatística Demógrafo-Sanitária. Além disso, o autor pondera que pode ter havido falhas nos registros feitos pelos médicos, que não atribuíram à influenza as causas que levavam o enfermo a óbito, tais como aquelas provocadas por infecções secundárias como a pneumonia e a broncopneumonia.

Assim, na tentativa de determinar o número de vítimas da epidemia, Bertolli Filho esquadrinhou os livros de cemitérios das dez necrópoles 
que existiam na cidade, comparando os dados obtidos com aqueles divulgados pelo Serviço Sanitário do Estado de São Paulo. Entretanto, ainda que tais informações não sejam exatas, o autor nelas se baseia para acompanhar a marcha da influenza, do ápice ao declínio, e situar os óbitos por essa doença nos diferentes espaços urbanos.

Após ter estabelecido o número aproximado de vítimas da influenza na capital paulista, Bertolli Filho se dedica a materializar a idéia esboçada no primeiro capítulo - a desconstrução do mito da mortalidade democrática pela epidemia de gripe espanhola. Segundo o autor, a influenza ainda é vista como uma moléstia que se relaciona mais "à sorte ou ao azar" do indivíduo do que a qualquer outro fator. $\mathrm{O}$ autor discorda desse pressuposto: afirma que a sobrevivência às enfermidades, sejam elas epidêmicas ou não, sofre a influência das condições materiais de vida próprias a cada grupo social.

Para comprovar sua tese, o autor estudou a distribuição da doença nos diferentes espaços geoeconômicos e sociais da Paulicéia. Partindo das informações sobre a procedência das vítimas, colhidas nos registros dos Livros de Cemitério, o autor desenhou um mapa da mortalidade por gripe, em São Paulo.

Todavia, para Bertolli Filho, os resultados obtidos ainda não eram satisfatórios, tendo em vista o elevado número de óbitos ocorridos no distrito da Consolação. Tal fato contrariava a idéia do autor, em razão da pretensão de demonstrar que as maiores vítimas da epidemia foram as camadas mais desfavorecidas da sociedade. Afinal, a Consolação era um distrito que abrigava as elites e que concentrava beneficia-mentos implementados pela administração pública e pela iniciativa privada.

Para explicar tal contradição, o autor elaborou duas hipóteses. A primeira considera que os óbitos registrados como procedentes do distrito da Consolação eram, na verdade, provenientes de outras localidades. Bertolli Filho apóia a sua conjectura no fato de que, nesse distrito, localizava-se o Hospital da Santa Casa de Misericórdia, que atendia a camada mais pobre da sociedade. Segundo o autor, os 144 óbitos, registrados no cartório cível e transcritos no Livro do Cemitério, declaravam como última residência das vítimas o endereço da Santa Casa, o que o levou a acreditar que se tratasse de pessoas pobres, residentes em outros distritos da cidade de São Paulo. Além disso, o autor observa que as famílias ricas que moravam naquele distrito dificilmente recorreriam ao Hospital da Santa Casa de Misericórdia, preferindo tratar seus enfermos no próprio domicílio ou em hospitais particulares.

A segunda hipótese apóia-se no argumento do sub-registro dos óbitos. O autor explica que os distritos suburbanos não contavam com serviços médicos permanentes, assim, no decorrer do período epidêmico, é provável que não tivessem sido computados todos os óbitos ocorridos naquela área. Como nem sempre se podia contar com a presença de médicos, para certificar a morte de alguém bastava a palavra de dois cidadãos de bem e a presença de um representante da polícia. Assim, grande parte dos óbitos eram atribuídos às causas naturais.

De acordo com o autor, no período da epidemia de gripe em São Paulo houve um aumento significativo nos registros de morte por causa 
natural. Bertolli Filho supõe que as mortes declaradas como naturais podem ter sido, na verdade, óbitos provocados pela influenza, concluindo que o total de falecimentos ocorridos na região tenha sido mais elevado do que aquele registrado pelo serviço de estatística.

Por fim, ao comparar os coeficientes de mortalidade dos distritos centrais com os dos periféricos, o autor verificou que a gripe ceifou mais vidas entre os pobres e os desvalidos, justamente aqueles que habitavam as áreas mais insalubres da capital paulista. Dessa maneira, o pesquisador acredita que tenha se desfeito a "ilusão democrática na distribuição dos óbitos provocados pela epidemia" (p. 93).

No capítulo IV, Bertolli Filho discute o conhecimento de que a ciência médica possuía a respeito da influenza, nas primeiras décadas do século XX. Segundo o autor, até as primeiras décadas do século XIX, tanto no Brasil quanto nos principais centros de pesquisa da Europa, a gripe era uma das patologias menos conhecidas e estudadas pela Medicina (p. 98).

Todavia, o autor menciona, em capítulo anterior, que a primeira epidemia de gripe ocorrida sob a égide da bacteriologia - 1889/1890 motivou destacados cientistas, tais como Pasteur e Koch, a investigarem a sua causa (p. 68). O bacteriologista alemão Richard Pfeiffer, a partir da análise do escarro dos gripados e da dessecação do aparelho respiratório das vítimas, conseguiu isolar, em 1892, o Haemophilus influenzae, conhecido como Bacilo de Pfeiffer (p. 68). Bertolli Filho argumenta, entretanto, que durante a pandemia de 1918 não havia unanimidade na comunidade médico-científica acerca do Haemophilus influenzae como agente etiológico daquela moléstia. Para muitos médicos trava-se de uma patologia nova, com quadro sintomático próprio, provocada por microrganismo ainda desconhecido.

Segundo o autor, a epidemia contribuiu para explicitar os discursos conflitantes que existiam sob a aparente coerência e convergência da medicina oficial. Diante da multiplicidade de percepções da moléstia que afloraram no decorrer da epidemia, outras formas de cura e de terapêuticas tomaram corpo na sociedade.

Para revelar as diferentes terapêuticas utilizadas no combate ao mal, o autor analisou as notícias, os anúncios de medicamentos e de serviços médicos publicados nos jornais da época, bem como o testemunho de memorialistas e entrevistados que vivenciaram o evento. Bertolli Filho conclui que a crise desencadeada pela gripe colocou em xeque e desarticulou o ideário da medicina oficial, abrindo caminho para propostas variadas que visavam mais o lucro que a cura da população acometida pelo morbo.

Nos capítulos seguintes o autor questiona a eficiência da organização sanitária de São Paulo no combate à epidemia, evidenciando as estratégias desenvolvidas pela sociedade paulistana para derrotá-la. Entra em cena a ação filantrópica de instituições como a Cruz Vermelha, a Santa Casa de Misericórdia, a Igreja Católica e a União dos Pastores Evangélicos, entre outras.

Nos últimos capítulos o autor se dedica a retratar o cotidiano da gripe e sua ação devastadora no município de São Paulo, expondo o medo da população diante de uma moléstia desconhecida e letal. As 
charges, bem como notícias fantásticas e sensacionalistas veiculadas em revistas e jornais, são as fontes utilizadas pelo autor para caracterizar esse quadro de pânico geral que se instaurou na Paulicéia.

O capítulo IX apresenta o fim da batalha contra a gripe como uma contenda em que os vencedores se sentiram derrotados. Para Bertolli Filho, a epidemia de gripe espanhola colocou em xeque o discurso triunfal da bacteriologia e expôs as limitações da ciência médica no sentido de identificar e combater um agente patogênico desconhecido.

Por fim, capítulo $X$ fala da memória da gripe - a gripe esquecida e a gripe lembrada - atribuindo às instâncias médicas e político-administrativas o interesse em olvidar a gripe. Para Bertolli Filho era importante para os políticos e para as autoridades médico-sanitárias manter a imagem de salubridade de uma cidade que se pretendia moderna e civilizada. Entretanto, o autor considera que aqueles que de alguma forma vivenciaram esse evento traumático trazem as suas marcas no corpo ou na memória.

O autor conclui a sua narrativa tendo atingido os objetivos a que se propôs - compreender o surto epidêmico e a distribuição socioeconômica da gripe na cidade de São Paulo, analisando as respostas coletivas, individuais e institucionais ao morbo. Essa história focaliza o momento em que o Estado, baseado em considerações além das relativas ao que é estritamente médico, se amolda a fatores políticos, sociais, econômicos e científicos, para criar e distribuir recursos de saúde pública. Contudo, para Bertolli Filho, a epidemia de gripe espanhola que se abateu sobre a cidade de São Paulo, entre 15 de outubro a 19 de dezembro, revelou os limites da medicina naquele início de século, as péssimas condições de vida da maioria da população e a precariedade do Serviço Sanitário paulista.

Assim, o livro se caracteriza como instrutivo não só porque atende aos que se interessam pela história de São Paulo, mas porque integra uma agenda de estudos atuais que enfocam o poder, o Estado, a profissão médica, as dimensões sociais e políticas do combate às epidemias, o desenvolvimento de políticas de saúde pública, a história da medicina e da biociência. A leitura fácil e instigante do texto de Bertolli Filho faz que renovados questionamentos sejam levantados, estimulando outros caminhos de investigação.

Nesse sentido, novas frentes de pesquisa têm direcionado a discussão para fora do eixo Rio-São Paulo, contemplando realidades distintas como a do Rio Grande do Sul, com trabalhos que narram o evento em outras cidades (Porto Alegre, Pelotas e Rio Grande), e a de Minas Gerais, com a narrativa da epidemia que flagelou a cidade salubre de Belo Horizonte. 


\section{NOTAS}

${ }^{1}$ Cf. Rosenberg, Charles E. "Introduction: Framing disease: Ilness, society and history". In: Rosenberg, Charles; Golden, Janet (ed.). Framing Disease - Studies in Cultural History. New Brunswick, Rutgers University Press, 1997; Slack, Paul. Introduction. In: Ranger, Terence; Slack, Paul. Epidemics and ideas: essays on the historical perception of pestilence. Cambridge, Cambridge University Press, 1992.

${ }^{2}$ Cf. Bertolli Filho, Cláudio. Epidemia e sociedade: a gripe espanhola no município de São Paulo. Dissertação de mestrado apresentada à Universidade de São Paulo, em 1986; Abrão, Janete S. A "espanhola" em Porto Alegre, 1918. Dissertação de mestrado apresentada à Pontifícia Universidade Católica do Rio Grande do Sul, em 1995; Olinto, Beatriz Anselmo. Uma cidade em tempo de epidemia. Rio Grande e a gripe espanhola (RS - 1918). Dissertação de mestrado apresentada à Universidade Federal de Santa Catarina, em 1996; Ferreira, Renata B. Epidemia e drama: a gripe espanhola em Pelotas - 1918. Dissertação de mestrado apresentada à Universidade Federal do Rio Grande, em 2001; Goulart, Adriana da C. Um cenário mefistofélico: a gripe espanhola no Rio de Janeiro. Dissertação de mestrado apresentada à Universidade Federal Fluminense em 2003; Bertucci, Liane Maria. Influenza: a medicina enferma. Tese de doutorado apresentada à Universidade Estadual de Campinas, em 2002; Silveira, Anny J. Torres. A influenza espanhola e a cidade planejada - Belo Horizonte, 1918. Tese de doutorado apresentada à Universidade Federal Fluminense, em 2004; Teixeira, Luiz Antônio. Medo e Morte: sobre a epidemia de gripe espanhola de 1918. Rio de Janeiro, UERJ/IMS, 1993; Brito, Nara Azevedo de. La dansarina: a gripe espanhola e o cotidiano na cidade do Rio de Janeiro. História, Ciências e Saúde - Manguinhos, vol. IV, n. 1, p. 11-30, mar./jun. 1997; Abrão, Janete Silveira. Banalização da morte na cidade calada: a hespanhola em Porto Alegre, 1918. Porto Alegre, Edipucrs, 1998; Ferreira, Renata Brauner. Epidemia e drama: a gripe espanhola em Pelotas - 1918. Rio Grande (RS), Fundação Universidade Federal do Rio Grande, 2001; Bertucci, Liane Maria. Influenza, a medicina enferma: ciência e práticas de cura na época da gripe espanhola em São Paulo. Campinas (SP), Ed. Unicamp, 2004; Crosby Jr., A. W. America's forgotten pandemic: The influenza of 1918. Cambridge, Cambridge University Press, 1999; Beveridge, W. I. B. Influenza. The Last Great Plague. London, Heinemann, 1977; Echeverri D’Ávila, Beatriz. La gripe española. La pandemia de 1918-1919. Madrid: Siglo XXI, 1993; Phillips, Howard; Killingray, David (ed.) The Spanish influenza pandemic of 1918-19: new perspectives. London and New York, Routledge, 2003; Pool, D. I. The effects of the 1918 pandemic of influenza on the Maori population of New Zeland. Bulletin of The History of Medicine, v. 47, n. 3, p. 273-81, May-June 1973; Tognotti, Eugenia. Scientific Triunphalism and Learning from Facts: Bacteriology and the "Spanish Flu" Challenge of 1918. Social History of Medicine, vol. 16, n. 1, 2003, entre outros.

${ }^{3} \mathrm{O}$ trabalho de Bertolli Filho é uma edição, revista e adaptada ao formato de livro, da dissertação de mestrado apresentada pelo autor à Faculdade de Filosofia, Letras e Ciências Humanas da Universidade de São Paulo, em 1986, intitulada Epidemia e sociedade: a gripe espanhola no município de São Paulo, já citada.

${ }^{4}$ Segundo Bertolli Filho, enfermidades como a febre tifóide, por exemplo, relacionada ao uso de águas poluídas por excrementos humanos, tinha uma incidência maior nos distritos operários onde havia deficiência no sistema de água e de esgoto.

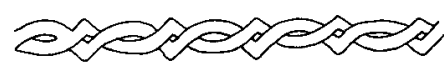




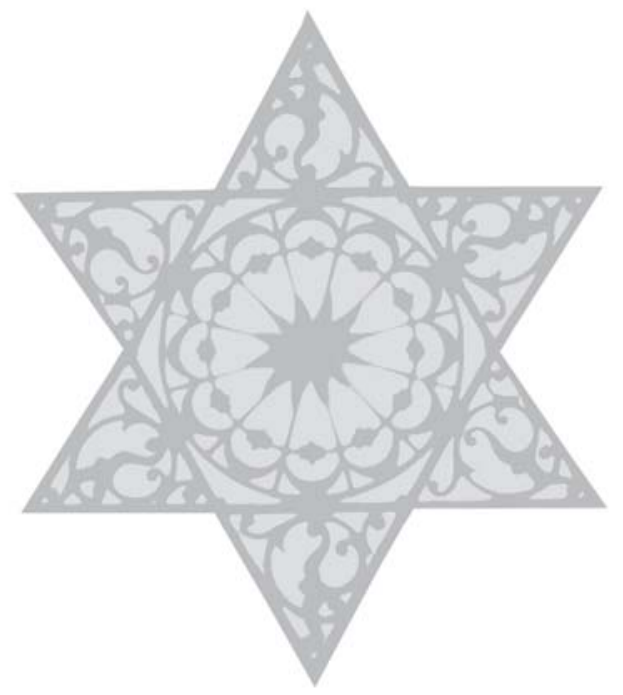

